\title{
SEGUIMIENTO A PROFESIONALES GRADUADOS DE LA URACCAN RECINTO LAS MINAS, GENERACIÓN 2001-2006 ${ }^{[1]}$
}

\author{
Letisia Castillo Gómez ${ }^{[2]}$, \\ Bismarck Lee León ${ }^{[3]}$ \\ Róger Benito Jarquin ${ }^{[4]}$
}

\section{Resumen}

Con el objeto de valorar la formación en el nivel de licenciatura, generación 2001-2006, de la Universidad de las Regiones Autónomas de la Costa Caribe Nicaragüense-URACCAN - Recinto Universitario Las Minas, se estudió el desempeño profesional. El Recinto Las Minas, se ubica en el barrio "Pedro Joaquín Chamorro", sector No. 3 del Municipio de Siuna, Región Autónoma Atlántico Norte. El Recinto Las Minas, posee tres extensiones universitarias en los municipios de Rosita, Bonanza y Waslala.

Se encuestaron a 208 profesionales de un total de 251 de esta generación. El 57\% corresponde al sexo femenino; el $11 \%$ pertenece a los pueblos indígenas miskitus y mayangnas; $89 \%$ de personas mestizas que constituyen mayoría y cuya edad promedio es de 36.41 años. La mayoría se localizan en el municipio de Siuna, y representan el 56.3\%; en Rosita el 28.5\%, en Bonanza el $10.8 \%$ y en menor proporción los municipios de Mulukukú, Waslala y Nindirí con el $1.9 \%, 1.3 \%$ y 0.6 respectivamente. Referente a la ocupabilidad se puede afirmar que el $91 \%$ de las personas graduadas se encuentran empleadas y son asalariadas en instituciones del sector estatal. Las personas mejor remuneradas monetariamente son los de la carrera de Ingeniería Agroforestal, seguida por la licenciatura en Ciencias Sociales con mención en Desarrollo Local.

Palabras claves: características de las personas graduadas, fortalezas y debilidades en las carreras cursadas, pertinencia de la formación.

\footnotetext{
[1] Investigación libre auspiciada por el gobierno de Austria a través de Horizont3000.

[2] Máster en Docencia Universitaria.

[3] Máster en Docencia Universitaria.

[4] Lic. en Matemáticas.
}

8 | CIENCIA E INTERCULTURALIDAD, Volumen 4, Año 2, No. 2, Junio 2009 


\section{Introducción}

La creciente exigencia por parte de los empleadores respecto a la excelencia en la formación profesional de las personas graduadas, obliga a las universidades a elevar la calidad en el proceso de formación y educación que desarrolla.

Desde hace décadas se fortalece a nivel internacional la tendencia de evaluación de la actividad universitaria, como una forma de rendición de cuentas a la sociedad y a los gobiernos. En ese contexto evaluativo, el seguimiento a egresados es un asunto vital para las universidades, ya que el desempeño profesional de las personas egresadas permite establecer indicadores con respecto a la calidad y eficiencia de las Instituciones de Educación Superior (Red GRADUA2/ Asociación Columbus, 2006).

La competitividad profesional representa el impacto y la pertinencia social de una institución de educación, así como en las comunidades donde viven y laboran forman parte de la misma, por cuanto se aporta en la construcción del proyecto de profesionalización durante toda la vida. Por tanto, graduado e institución siguen teniendo lazos de afinidad sin cuestionamientos de tiempo y distancia.

Desde la sociedad, las personas graduadas constituyen testimonios de calidad en la relación de programas e institución, conjuntamente con la producción científica y tecnológica, y con otras evidencias del quehacer académico y social. Por lo tanto, las demandas que se le hacen a la Educación Superior pueden sintetizarse en un gran objetivo: Mejorar la calidad de la formación para garantizar a la sociedad profesionales idóneos para resolver los problemas de índole social, económica, política y cultural (Landeo y Wanuz, 2005).

Los egresados son la mejor proyección social de la URACCAN; su inserción en el mercado laboral, el desempeño profesional específico, las realizaciones y reconocimientos alcanzados testimonian la calidad de la formación recibida. Por todo ello, el examen minucioso de sus condiciones de trabajo, de sus trayectorias laborales, académicas y sociales, constituyen valiosos indicadores sobre la calidad de las carreras ofrecidas y fuente importante de reflexión para la Universidad misma (Jaramillo; Ortiz; Zuluaga; Almonacid y Acebedo, 2002).

La URACCAN, tiene como misión contribuir al fortalecimiento del proceso de la Autonomía de la Costa Caribe nicaragüense, mediante la capacitación y profesionalización de Recursos Humanos, dotándolos de los conocimientos necesarios para conservar y aprovechar de forma racional y sostenida los Recursos Naturales. 


\section{LA EDUCACIÓN SUPERIOR EN LA REGIÓN AUTÓNOMA ATLÁNTICO NORTE}

En doce años de funcionamiento ha formado nuevos profesionales, que aportan a la cultura de las comunidades los valores que inspiran sus procesos académicos y administrativos, y quienes se convierten en la prolongación social de la Universidad, ya no como centro de formación, sino como actor del desarrollo integral de la comunidad en la que participa y de quienes no se ha realizado una medición del impacto que efectúan con su desempeño en los distintos ámbitos profesionales y sociales, en las cuales despliegan las competencias de formación y reflejan la calidad del proceso de enseñanza aprendizaje.

Los estudios sobre seguimiento de graduados constituyen un aporte fundamental en la búsqueda de la calidad en todo el quehacer de la educación superior. Para el caso de Centroamérica, el seguimiento de graduados ha sido un reto insoslayable, pues éste ha sido una carencia detectada en la mayoría de los procesos de autoevaluación y evaluación externa llevados a cabo en diferentes universidades de la región.

Este tipo de estudios aporta a las universidades elementos fundamentales para el mejoramiento de sus programas académicos y de la organización para su desarrollo. De modo que no pueden omitirse en los procesos de aseguramiento de la calidad de la Educación Superior, sino que deben constituirse en uno de los pilares fundamentales de estos procesos (Medina, 2004).

Bajo esta perspectiva, realizamos un estudio de seguimiento a la comunidad estudiantil graduada en los municipios del Triángulo Minero hasta el año 2006, permitiendo iniciar un proceso de seguimiento sistemático por parte de nuestra institución, que permitiera obtener información para indicar las fortalezas y deficiencias para realizar las innovaciones pertinentes a nivel curricular para mejorar la oferta de enseñanza y formación y que sirva de base para futuras actividades de planificación institucional.

\section{Revisión de literatura}

La URACCAN es una institución generadora de pensamiento propio, transformadora y con proyección hacia la vida social. Es a su vez generadora de humanismo, custodia de la verdad y de la ciencia al margen de posturas ideológicas.

Se integra a la sociedad por medio de sus egresados, de quienes espera sean el vehículo mediante el cual el espíritu universitario logre penetrar en ella. Si logra que sus egresados interactúen en sociedad, poseídos del espíritu universitario, crítico y humanista, con pensamiento autónomo y con una ética impregnada del sentido de 
justicia, equidad, tolerancia y autocrítica, la universidad será útil y provechosa para su sociedad (Parent; Esquivel; Farrand; Massé y Pérez, 2003).

Los mismos autores determinan que las funciones sociales de la universidad pueden resumirse en lo siguiente:

a. Preparar individuos capaces de dar en la interacción social lo mejor del espíritu universitario: el respeto y el diálogo con sus interlocutores;

b. Ponderar y generar el deseo por la verdad en el saber y en el conocimiento, para que convertidos en valores, trasciendan el espacio universitario llegando a la sociedad;

c. Promover en la sociedad valores de justicia y equidad, que son los que emanan del sentimiento democrático.

La UNESCO (1995) fija posición sobre el "deber ser" de una universidad en el siglo XXI (dinámica-proactiva) al considerar para ello:

1. Un lugar de formación de alta calidad, donde el acceso dependa del mérito intelectual.

2. Una comunidad dedicada a la investigación, creación y difusión del conocimiento.

3. Un lugar donde se promueva el auto-aprendizaje y la responsabilidad social.

4. Un lugar que actualice y perfeccione a sus egresados.

5. Una comunidad que apoye activamente la cooperación con la industria.

6. Un lugar donde se discutan problemas y soluciones locales, regionales, nacionales e internacionales.

7. Un lugar donde el gobierno y demás instituciones públicas encuentren información científica y viable y que también provea la participación en el proceso de la toma de decisiones.

8. Una comunidad comprometida con sus valores tradicionales.

9. Bien ubicada en el contexto mundial y a las características distintivas de cada región y de cada país.

Cualquier estudio sobre egresados se inscribe en el contexto de la evaluación de la calidad de los programas y procesos educativos de formación y, por tanto, de la institución que otorga el título (Jaramillo; Ortiz; Zuluaga; Almonacid y Acebedo, 2002).

Una calidad que se manifiesta en las competencias desarrolladas, en los desempeños de profesionalidad y mejoramiento de las condiciones de empleabilidad de los 


\section{LA EDUCACIÓN SUPERIOR EN LA REGIÓN AUTÓNOMA ATLÁNTICO NORTE}

egresados y la productividad de las empresas, así como en la adecuada respuesta a los requerimientos de sujetos de atención diversa: individuos, empresas, sectores y cadenas productivas, comunidades, etc.

Se requiere, en definitiva, de una formación para la empleabilidad, entendida tal como lo plantea el Convenio 195 de la OIT como el conjunto de

“competencias y cualificaciones transferibles que refuerzan la capacidad de las personas para aprovechar las oportunidades de educación y formación que se les presenten con miras a encontrar y conservar un trabajo decente, progresar en la empresa o al cambiar de empleo y adaptarse a la evolución de la tecnología y de las condiciones del mercado de trabajo" (Artículo 3.d).

En este sentido, la calidad de la formación impartida se manifiesta no sólo por la coherencia académica entre teoría y práctica, sino también por la viabilidad del ejercicio profesional, que permite demostrar las competencias adquiridas. Por esta razón, en el estudio también se consulta la opinión de los egresados sobre la calidad de la formación recibida, expresada en su satisfacción con el programa cursado, la pertinencia laboral y su importancia para la sociedad (Jaramillo; Ortiz; Zuluaga; Almonacid y Acebedo, 2002).

\section{Materiales y métodos}

La Universidad de las Regiones Autónomas de la Costa Caribe Nicaragüense URACCAN-, se constituye como universidad privada sin fines de lucro, y se define como una Universidad intercultural, comunitaria y de servicio público, cuya Visión se centra en que es la Universidad intercultural de los pueblos indígenas y comunidades étnicas de la Costa Caribe nicaragüense a través del acompañamiento de procesos de autogestión, unidad multiétnica y la formación integral de mujeres y hombres de la Costa Caribe.

Desde inicio de 1995 hasta el año 2006, 580 mujeres y hombres, en su mayoría de escasos recursos económicos, se han graduado en el Recinto Universitario Las Minas, en las modalidades de pregrado (licenciaturas o su equivalente y de técnico Superior), en los municipios de Rosita, Bonanza y Siuna (sede principal). De estos, en el nivel de licenciatura son 251 graduadas/os en el período 2001 al 2006 en 8 carreras. Significando un graduado, una persona que ha recibido una formación académica o profesional, que le provee competencias laborales, bajo la influencia de ciertos valores, creencias, 
costumbres, actitudes y prácticas, que le transmite nuestro sello institucional y que influyen en su inserción y desempeño en la sociedad.

\section{Enfoque de la investigación: mixto}

Tipo de Investigación: Descriptiva, transversal ya que la población de graduadas/os es encuestada solamente una vez en un tiempo definido.

\section{Población y muestra}

La población objeto de estudio se enmarcó en los 251 graduadas/os del nivel de licenciatura de la Universidad de las Regiones Autónomas de la Costa Caribe Nicaragüense, Recinto Universitario Las Minas, comprendidos en el período 2001-2006. Para seleccionar la muestra cuantitativa se realizó un muestreo estratificado considerando seis estratos: Graduadas/os de la carrera de Administración de Empresas, Ciencias de la Educación, Sociología, Ciencias Sociales con mención en Desarrollo Local, Ingeniería Agroforestal e Ingeniería en Zootecnia.

El tamaño de la muestra se calculó mediante el empleo de la fórmula que define el número de muestra "n" para poblaciones conocidas:

$$
n=\frac{p^{*} q}{\frac{E^{2}}{z^{2}}+\frac{p^{*} q}{N}}
$$

Donde:

$\mathrm{n}=$ Tamaño de la muestra.

$\mathrm{p}=$ probabilidad de ocurrencia de un evento.

$\mathrm{q}=$ probabilidad de no ocurrencia de un evento.

$\mathrm{E}=$ Margen de error

$Z=$ Nivel de confianza.

$\mathrm{N}=$ Población de interés.

Para esta investigación se establece un nivel de confianza del 95\% $(Z=1.96)$, un margen de error del $3 \%$, la probabilidad de ocurrencia o no ocurrencia es de 0.5 y utilizando la población de interés definida anteriormente aplicando la fórmula anterior, se determina que el tamaño de la muestra fue de 208. 


\section{LA EDUCACIÓN SUPERIOR EN LA REGIÓN AUTÓNOMA ATLÁNTICO NORTE}

$(0.5)(0.5) 0.250 .250 .25$

$\underline{n}$ 三ニニニニニニニニニニニニニニニニーーニニー-ー-ーーニシーーニ $\equiv 208$

$0.03^{2}(0.5)(0.5) 0.00090 .250 .0003+0.00090 .0012$

$1.96^{2} 2513.8416251$

Para la estratificación se usó la fórmula siguiente $\mathrm{Ksh}=\mathrm{n} / \mathrm{N}$; que es la fórmula que se usa para estratificar.

Como el muestreo es estratificado, para cada estrato se tomó una sub-muestra, mediante el proceso aleatorio simple, de tal manera que se aplicaron las encuestas al azar. Esto se realizó fundamentalmente para señalar la pertinencia del área de formación frente a la ocupabilidad.

Para seleccionar a las personas graduadas de cada carrera se empleó el muestreo probabilístico o la técnica aleatoria simple y se realizaron los pasos siguientes:

1. Se realizó un listado de todas las personas graduadas que conforman el universo por estratos.

2. Se elaboraron papelitos que contenían la numeración correspondiente por estratos.

3. Se introdujeron todos los papelitos en una bolsa.

4. Se extrajeron $\mathbf{N}$ papelitos para cada una de los estratos.

5. Se elaboró la lista con los nombres de personas graduadas seleccionadas.

\section{Etapas}

Comprendió tres etapas: acopio y sistematización de la información requerida, procesamiento de la información con el programa estadístico SPSS; análisis de esta información y emisión de un juicio fundamentado y de recomendaciones para tomar decisiones.

14 | CIenCia e interCulturalidad, Volumen 4, Año 2, No. 2, Junio 2009 


\section{Resultados y discusión}

\section{Caracterización de las personas graduadas en el nivel de licenciatura de URACCAN Las Minas generación 2001 - 2006}

La Universidad de las Regiones Autónomas de la Costa Caribe Nicaragüense URACCAN - Las Minas en su trayectoria institucional de Educación Superior hasta el 2006 ha formado y titulado a 251 profesionales en el nivel de licenciatura en 8 carreras: Ingeniería Agroforestal, Licenciatura en Administración de Empresas, Licenciatura en Sociología, Licenciatura en Educación Intercultural Bilingüe, Licenciatura en Ciencias Sociales con mención en Desarrollo Local, Licenciatura en Ciencias de la Educación con mención en Biología, Licenciatura en Ciencias de la Educación con mención en Historia e Ingeniería en Zootecnia.

Estas 251 graduaciones están distribuidas según sexo de la siguiente forma:

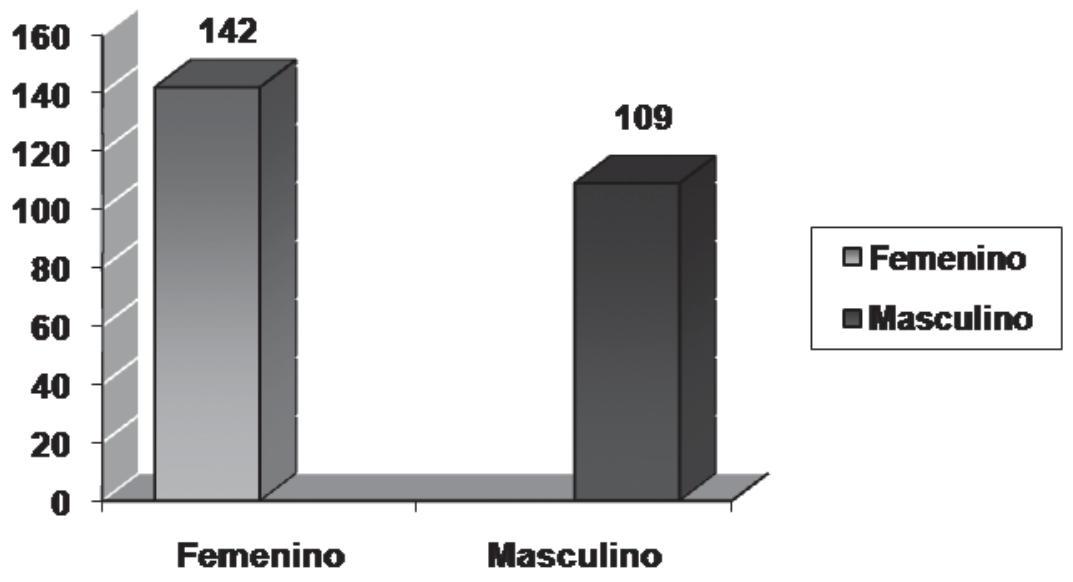

Figura 1: Cantidad de graduaciones: generación 2001-2006, nivel de licenciatura por sexo.

Los datos anteriores alteran la tradición, de que la Educación Superior no fue un espacio considerado propiamente "femenino", constituyendo uno de los ámbitos privilegiados de reproducción de las desigualdades de género en el fortalecimiento de la división sexual del trabajo. De esta forma, los varones eran quienes accedían a los Estudios Superiores como parte de su integración exitosa a la esfera pública y 


\section{LA EDUCACIÓN SUPERIOR EN LA REGIÓN AUTÓNOMA ATLÁNTICO NORTE}

reconocimiento social, mientras las mujeres eran invisibilizadas en la esfera privada y asignadas a las tareas propias de la reproducción y cuidados de la familia y el hogar.

Como se expresó anteriormente, la población de graduadas/os está constituida en un $57 \%$ por mujeres, aunque la distribución por género varía entre carreras; así, por ejemplo, en Ingeniería Agroforestal los hombres representan el 73.2\% de los titulados, mientras que en Sociología, Administración de Empresas y Ciencias de la Educación predominan las mujeres, con el $91.4 \%, 85.4 \%$ y $58.5 \%$ respectivamente.

El 11\% pertenece a los pueblos indígenas miskitus y mayangnas, los mestizos representan el $89 \%$ y constituyen mayoría; se puede inferir que en este Recinto Universitario acceden y egresan menos indígenas y más mestizos, esto pudiera ser por la zona de influencia del recinto, connotando la existencia de los cuatros grupos étnicos que reflejan la multiculturalidad de nuestra Región.

La edad promedio para el total de titulados es de 36.41 años, la edad más representativa es 30 años siendo la mínima 23 años y 62 años la máxima, esta última no muy representativa.

La comunidad estudiantil graduada de las carreras de Ciencias de la Educación y Sociología son los de mayor edad, debido a que estos fueron en su mayoría trabajadores de las instituciones del municipio que anhelaban la profesionalización.

La mayoría de las personas graduadas se pueden localizar en el municipio de Siuna, el $56.3 \%$ vive actualmente en este municipio, el $28.5 \%$ en el municipio de Rosita, el $10.8 \%$ en Bonanza y en menor proporción en los municipios de Mulukukú, Waslala y Nindirí (1.9\%, $1.3 \%$ y 0.6 respectivamente).

Los datos anteriores concuerdan con el Informe sobre la Educación Superior en América Latina y el Caribe 2000-2005, el cual expresa que con las profundas transformaciones ocurridas en las universidades latinoamericanas, expresadas en un proceso de masificación, feminización, privatización, regionalización, diferenciación y segmentación, sumado a los propios cambios de esas sociedades sumidas en un proceso de urbanización, cambio demográfico, transformación productiva y apertura económica, cambiaron sustancialmente el rol y las características de los estudiantes. 
Tal proceso expresa una creciente masificación de la Educación Superior que se manifiesta en cambios del perfil social del estudiantado: feminización, estudiantes del interior de las comunidades, estudiantes como clientes, estudiantes de corto tiempo, estudiantes profesionales, estudiantes trabajadores, estudiantes a distancia, estudiantes indígenas, diversidad de pueblos, estudiantes con discapacidades, junto a los tradicionales estudiantes.

Las 251 personas graduadas, son de 8 carreras desarrolladas en el recinto, específicamente se distribuyen de la siguiente forma:

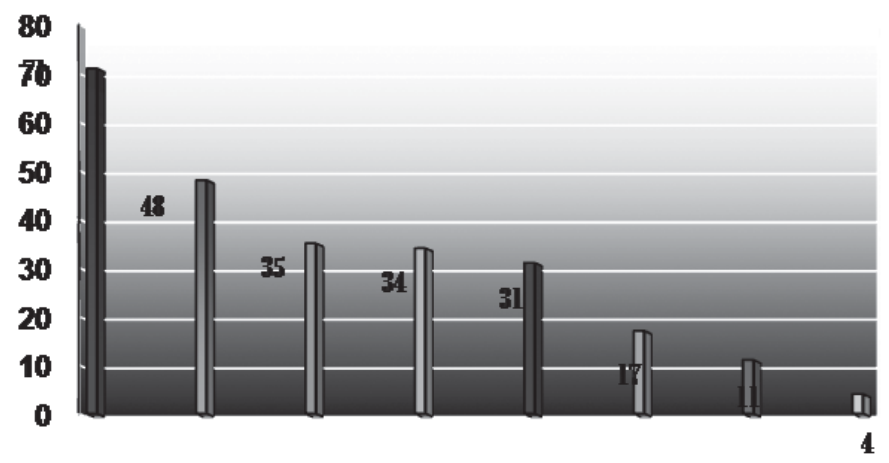

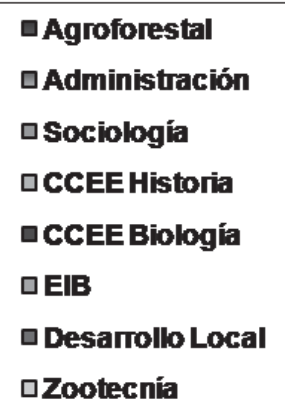

Figura 2: Distribución de las graduadas y los graduados, generación 2001 - 2006 por carrera.

Como se observa en el gráfico anterior, las carreras con mayor número de graduaciones son las de Ingeniería Agroforestal, Licenciatura en Administración de Empresas y Licenciatura en Sociología, esto se debe a que son las carreras más antiguas de nuestro Recinto Universitario, es decir son las que se aperturaron con el inicio de la universidad y se siguen ofertando a excepción de Sociología.

En términos de tasas de crecimiento en cuanto al número de graduaciones anuales, cabe decir que las carreras registran dinámicas diferentes como se puede observar en el siguiente cuadro: 


\section{LA EDUCACIÓN SUPERIOR EN LA REGIÓN AUTÓNOMA ATLÁNTICO NORTE}

Cuadro 1: Número de graduaciones anuales por carrera de URACCAN Las Minas, generación 2001-2006.

\begin{tabular}{|c|c|c|}
\hline Carrera & Año & Número de graduadas/os \\
\hline \multirow{6}{*}{ Ingeniería Agroforestal } & 2001 & 8 \\
\hline & 2002 & 5 \\
\hline & 2003 & 17 \\
\hline & 2004 & 11 \\
\hline & 2005 & 18 \\
\hline & 2006 & 12 \\
\hline \multirow{6}{*}{$\begin{array}{l}\text { Licenciatura en } \\
\text { Administración de Empresas }\end{array}$} & 2001 & 12 \\
\hline & 2002 & 6 \\
\hline & 2003 & 10 \\
\hline & 2004 & 4 \\
\hline & 2005 & 2 \\
\hline & 2006 & 14 \\
\hline \multirow{5}{*}{$\begin{array}{l}\text { Licenciatura en Sociología } \\
\text { con mención en Autonomía }\end{array}$} & 2001 & 13 \\
\hline & 2002 & 5 \\
\hline & 2003 & 5 \\
\hline & 2004 & 8 \\
\hline & 2005 & 4 \\
\hline \multirow{4}{*}{$\begin{array}{l}\text { Licenciatura CCEE con men- } \\
\text { ción en Historia }\end{array}$} & 2003 & 10 \\
\hline & 2004 & 2 \\
\hline & 2005 & 17 \\
\hline & 2006 & 5 \\
\hline \multirow{4}{*}{$\begin{array}{l}\text { Licenciatura CCEE con men- } \\
\text { ción en Biología }\end{array}$} & 2003 & 10 \\
\hline & 2004 & 0 \\
\hline & 2005 & 15 \\
\hline & 2006 & 6 \\
\hline $\begin{array}{l}\text { Licenciatura en Educación } \\
\text { Intercultural Bilingüe }\end{array}$ & 2004 & 17 \\
\hline \multirow{2}{*}{$\begin{array}{l}\text { Licenciatura en Ciencias } \\
\text { Sociales con mención en } \\
\text { Desarrollo Local }\end{array}$} & 2005 & 9 \\
\hline & 2006 & 2 \\
\hline Ingeniería en Zootecnia & 2006 & 4 \\
\hline
\end{tabular}

18 | CIencia E INTERCULturalidad, Volumen 4, Año 2, No. 2, Junio 2009 
Al encuestar a las graduadas y los graduados con respecto a su situación laboral obtuvimos los datos siguientes:

\section{¿Trabaja Actualmente?}

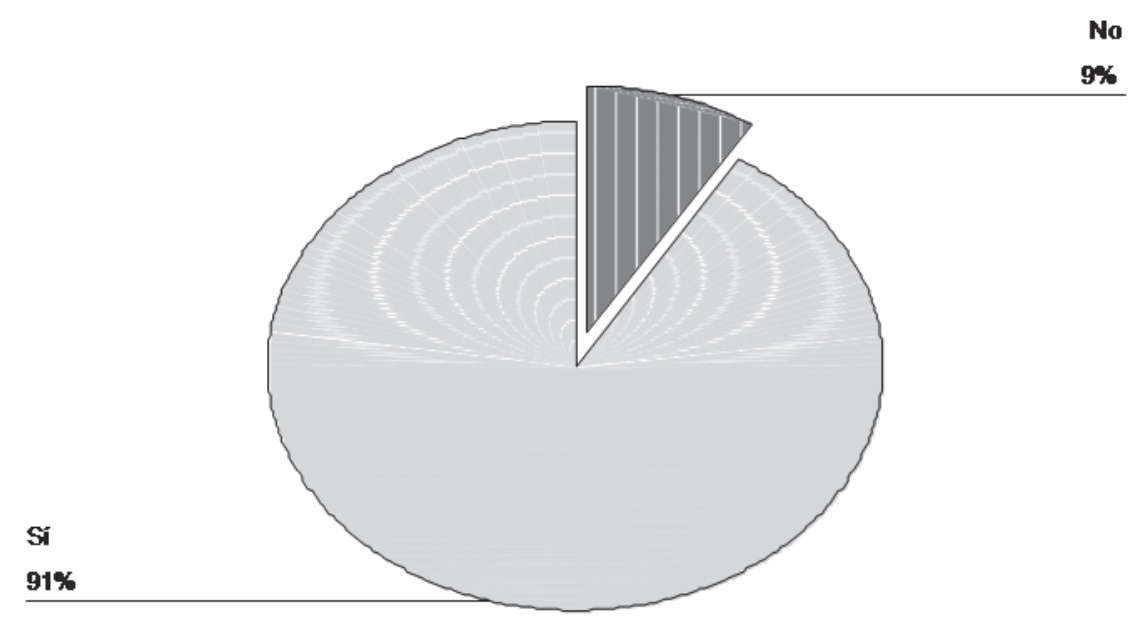

Figura 2: Condición laboral de las graduadas y graduados, generación 2001 - 2006 al momento de la encuesta

Lo cual significa que la mayoría de las personas graduadas de la generación 2001-2006 están empleadas, esto es satisfactorio para la URACCAN ya que cuando un graduada/o ingresa al mercado laboral, lleva consigo no sólo una impronta, que lo define como persona y como profesional, sino que - como producto lleva una marca y es ésta la que será demandada o no por las empresas y organizaciones.

Los datos observados en el gráfico No. 2 coinciden con lo planteado en el Informe sobre la Educación Superior en América Latina y el Caribe 2000-2005, que en América Latina, los sectores sociales con nivel educativo terciario que buscan trabajo y no lo encuentran -por tanto en condición de desempleo son minoritarios, no superando el 10\% de acuerdo a los últimos datos disponibles.

Las posibilidades laborales están condicionadas según el grado de aceptación y posicionamiento (hablando en términos de mercadeo), de esa marca; con ella, el egresado no sólo ofrece su capacidad de trabajo, sino todo un testimonio institucional de calidad y de imagen en el mercado laboral. 


\section{LA EDUCACIÓN SUPERIOR EN LA REGIÓN AUTÓNOMA ATLÁNTICO NORTE}

La pregunta por las posibilidades laborales, derivadas del hecho de haber obtenido el título en la Universidad, puede ser, por sí sola, un buen indicador de la calidad de la Institución, pues las posibilidades laborales de los egresados son el resultado de la interacción entre el prestigio de la Universidad, la pertinencia de su formación y la satisfacción de la formación recibida.

En términos generales, la mayor parte de las personas graduadas de la URACCAN son asalariadas (88.06\%), seguidos por quienes ocupan una posición de patrones o empleadores de su propio negocio (5.84\%).

En cuanto al tipo de institución en donde trabajan, más de la mitad (75\%) de la generación graduada entre 2001-2006 se encuentran laborando en instituciones del sector estatal, el resto se ubica en organizaciones privadas y otros.

En relación con las funciones desarrolladas por las personas encuestadas, se encontró que mayoritariamente se encuentran desempeñando funciones docentes y administrativas.

La información relacionada con los salarios promedios que reciben mensualmente las graduadas y graduados por carreras se presenta en el siguiente gráfico:

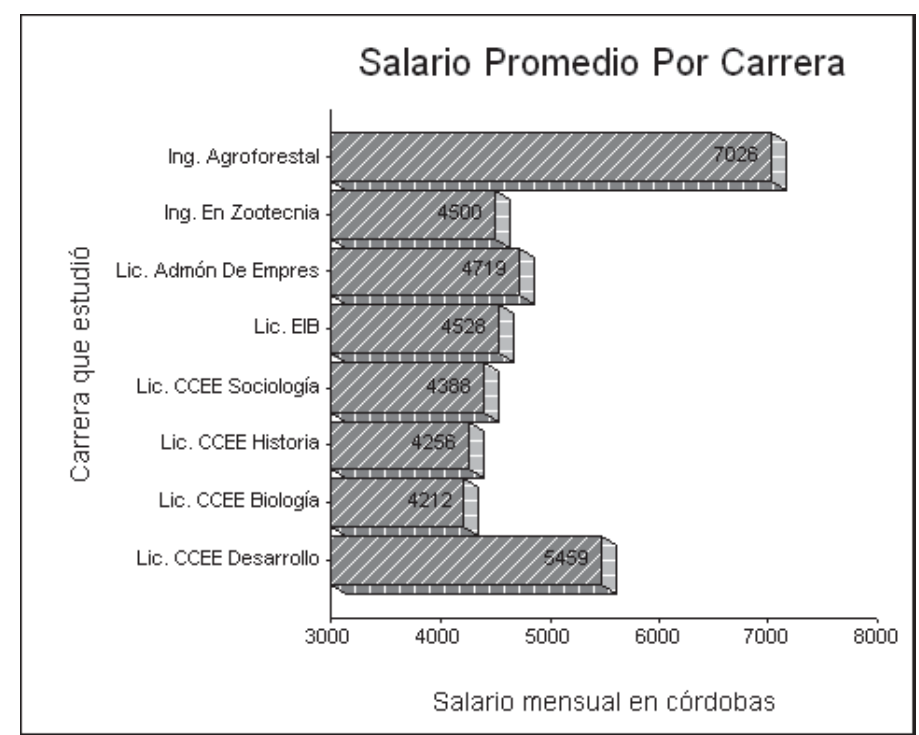

Figura 3: Salarios promedios por carrera de los graduados y las graduadas de la generación 2001-2006. 
En la generación de las personas graduadas que son mejor remuneradas monetariamente son las de la carrera de Ingeniería Agroforestal seguida por la Licenciatura en Ciencias Sociales con mención en Desarrollo Local (C\$ 7026.00 y C\$ 5459.00 respectivamente).

$\mathrm{Al}$ analizar específicamente por carrera se obtuvo que el salario mensual mínimo de la carrera de Ingeniería Agroforestal es de $C \$ 1823.84$ y el máximo $C \$ 17400.00$, en la Licenciatura en Administración de Empresas, mínimo $C \$ 700.00$, máximo $C \$ 12$ 600.00 , en la Licenciatura en Sociología, mínimo $C \$ 1360.00$, máximo $C \$ 15,350.00$, en la Licenciatura en Ciencias de la Educación con mención en Historia el mínimo es de $C \$ 2153.00$ y el máximo $C \$ 8040.00$, en la Licenciatura en Ciencias de la Educación con mención en Biología el mínimo es de $C \$ 2883.70$ y el máximo es de $C \$ 5882.61$, en la Licenciatura en Ciencias Sociales con mención en Desarrollo Local mínimo C \$ 3300.00 máximo $C \$ 7525.25$, en la Licenciatura en Educación Intercultural Bilingüe mínimo $C \$ 2800.00$ máximo $C \$ 7402.50$ y en Ingeniería en Zootecnia mínimo $C \$$ 4000.00 máximo $C \$ 4500.00$.

Los salarios mínimos descritos anteriormente por carreras sólo lo reciben el 5\% de las graduadas y graduados de la generación 2001-2006, también podemos resaltar que los salarios más altos sólo son recibidos por el $5 \%$.

Según los datos obtenidos las graduadas y graduados que perciben mejores salarios son los de la carrera de Ingeniería Agroforestal, esto puede deberse al amplio perfil de esta carrera que hace que estos profesionales tengan una diversa gama de posibilidades de ocupabilidad, mientras que los más bajos corresponden a las Ciencias de la Educación.

\section{Pertinencia del área de formación frente a la ocupabilidad}

Al calificar la pertinencia laboral se acepta que la calidad de la Universidad se refleja en la capacidad de formar personas competentes para dar respuestas a las exigencias del medio, con las características necesarias para hacer del conocimiento un motor de desarrollo y beneficiar a las empresas y a la sociedad.

Existe una valoración generalizada muy alta al considerar el grado de relación del trabajo que desempeñan las graduadas y los graduados con las carreras cursadas.

Al analizar la relación entre la formación recibida y el trabajo, se distinguen quienes cursaron las carreras de Ciencias de la Educación con mención en Historia e Ingeniería en Zootecnia, el 100\% están ocupados según el perfil de la carrera. Los 


\section{LA EDUCACIÓN SUPERIOR EN LA REGIÓN AUTÓNOMA ATLÁNTICO NORTE}

demás aunque están trabajando un gran porcentaje no se encuentra desempeñándose según la carrera.

Es válido destacar que si es cierto que las/os ingenieras/os agroforestales están recibiendo los mejores salarios, estos en un gran porcentaje (76\%) no están realizando un trabajo relacionado con la formación recibida, aunque si les ha servido para su vida y el $89 \%$ se sienten satisfechos con la formación recibida en la universidad.

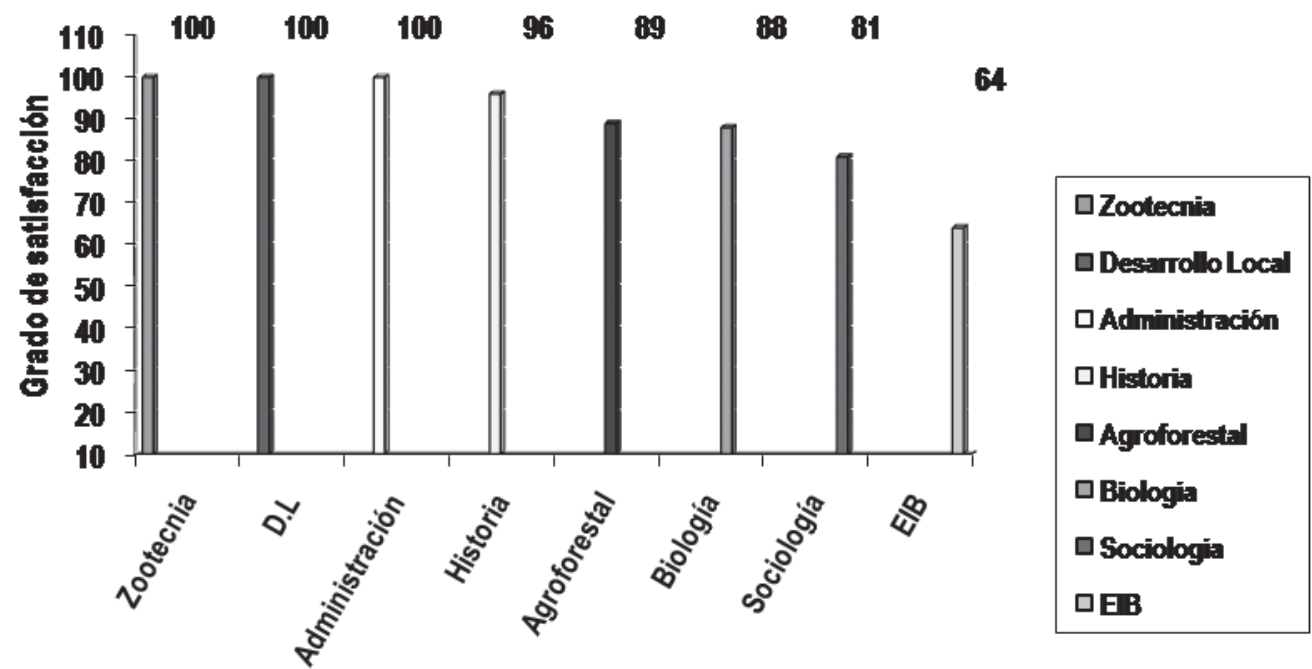

\section{Carreras}

Figura 4: Satisfacción de los y las graduadas de URACCAN Las Minas generación 2001-2006 con la formación recibida por carrera.

De manera general el 90\% de las personas graduadas de URACCAN Las Minas se sienten satisfechas con la formación recibida.

A pesar de que el grupo de ex estudiantes insatisfechos es reducido, las razones de esa insatisfacción es muy variada entre las cuales se encuentran: falta de actividades de laboratorio, contenidos muy teóricos, enfoque regional, la falta de fomento por la innovación, el emprendimiento y de paquetes estadísticos.

La mayoría de las personas graduadas de URACCAN se sienten satisfechas y expresan un gran agradecimiento por la formación recibida en la Universidad. 
"La formación recibida en la universidad me ha ayudado a integrarme mejor como agente de cambio en la comunidad".

"Afirmo que he tenido la oportunidad de sentirme realizada en lo profesional y en lo personal".

"Mi desempeño laboral ha sido mejor".

"Estoy en condiciones de demostrar en cualquier parte que tengo una buena formación y al mismo tiempo estoy orgulloso por ser uno de los primeros graduados de URACCAN".

"La universidad nos preparó para realizar múltiples actividades y estoy consciente y seguro que no voy a defraudar la formación que recibí"

"La formación recibida en la universidad permitió que mi desempeño cambiara para bien de la comunidad educativa".

"Mi sueño ya es realidad".

"Gracias a la universidad hoy en día soy lo que soy, tengo mi trabajo y vivo feliz con mi familia".

"De no haberme profesionalizado en URACCAN hoy en día estuviese trabajando en la minería artesanal".

“Con el tiempo que estuve en URACCAN aprendí que tan importante es crecer profesionalmente sin distinguir raza, color, religión y política”. 


\section{LA EDUCACIÓN SUPERIOR EN LA REGIÓN AUTÓNOMA ATLÁNTICO NORTE}

Cuadro 3: Fortalezas y debilidades de las carreras

\begin{tabular}{|c|c|c|}
\hline Carrera & $\begin{array}{c}\text { Fortalezas del perfil } \\
\text { profesional para } \\
\text { empleo }\end{array}$ & $\begin{array}{c}\text { Debilidades del perfil } \\
\text { profesional para empleo }\end{array}$ \\
\hline Ingeniería Agroforestal & $\begin{array}{l}\text { Enfoque en desarrollo } \\
\text { Comunitario, administrati- } \\
\text { vo y medio ambiente. } \\
\text { Marco Jurídico Ambiental. } \\
\text { Enfoque regional (Trópico } \\
\text { Húmedo). } \\
\text { Informática. }\end{array}$ & $\begin{array}{l}\text { Falta de experiencia profesional. } \\
\text { Enfoque regional (Trópico } \\
\text { Húmedo). } \\
\text { La falta de fomento innovación y el } \\
\text { emprendimiento. } \\
\text { Poco enfoque agrícola. } \\
\text { Prácticas de campo. } \\
\text { Poco uso y manejo de los medios } \\
\text { tecnológicos en práctica de cam- } \\
\text { po. } \\
\text { Idioma. } \\
\text { Paquetes en informática de recur- } \\
\text { sos naturales. } \\
\text { Manejo del personal. } \\
\text { Inclinación del currículo al área } \\
\text { forestal. } \\
\text { Poco conocimiento sobre manejo } \\
\text { y aprovechamiento de áreas pro- } \\
\text { tegidas. }\end{array}$ \\
\hline Ingeniería en Zootecnia & $\begin{array}{l}\text { Enfoque regional (Trópico } \\
\text { Húmedo). }\end{array}$ & $\begin{array}{l}\text { Falta de aspectos administrativos y } \\
\text { financieros. } \\
\text { Prácticas de campo. }\end{array}$ \\
\hline $\begin{array}{l}\text { Licenciatura en } \\
\text { Sociología con men- } \\
\text { ción en Autonomía }\end{array}$ & $\begin{array}{l}\text { Docencia. } \\
\text { Dirigir instituciones so- } \\
\text { ciales. } \\
\text { Trabajar en investigacio- } \\
\text { nes. } \\
\text { Trabajo social. } \\
\text { Planificación, monitoreo y } \\
\text { evaluación de procesos. } \\
\text { Amplio campo de aplica- } \\
\text { ción social. }\end{array}$ & $\begin{array}{l}\text { La mención del título (autonomía) } \\
\text { no lo reconoce el MINED. } \\
\text { Falta de aspectos administrativos y } \\
\text { de gerencia. }\end{array}$ \\
\hline
\end{tabular}




\begin{tabular}{|c|c|c|}
\hline Carrera & $\begin{array}{l}\text { Fortalezas del perfil } \\
\text { profesional para } \\
\text { empleo }\end{array}$ & $\begin{array}{l}\text { Debilidades del perfil } \\
\text { profesional para empleo }\end{array}$ \\
\hline $\begin{array}{l}\text { Licenciatura en Ciencias } \\
\text { de la Educación con } \\
\text { mención en Biología }\end{array}$ & $\begin{array}{l}\text { Mejor desempeño do- } \\
\text { cente. } \\
\text { Fortalecimiento de la } \\
\text { Educación. } \\
\text { Proceso de enseñanza } \\
\text { aprendizaje mejorado. } \\
\text { Educación ambiental. } \\
\text { Respeto a la pluricultura- } \\
\text { lidad. } \\
\text { Preparación para trabajar } \\
\text { con diferentes grupos de } \\
\text { edades. } \\
\text { Los ejes transversales de } \\
\text { la universidad. }\end{array}$ & $\begin{array}{l}\text { Falta de práctica de laboratorios y } \\
\text { bibliografía. } \\
\text { Idioma (Inglés). } \\
\text { Informática. }\end{array}$ \\
\hline $\begin{array}{l}\text { Licenciatura en Ciencias } \\
\text { de la Educación Historia }\end{array}$ & $\begin{array}{l}\text { Mejor desempeño do- } \\
\text { cente. } \\
\text { Desempeño profesional } \\
\text { en los diferentes niveles } \\
\text { de Educación. } \\
\text { Capacitador/a. } \\
\text { Las Metodologías. } \\
\text { Asesor/a. }\end{array}$ & $\begin{array}{l}\text { Desarrollo de la ética como un } \\
\text { valor humano. }\end{array}$ \\
\hline $\begin{array}{l}\text { Licenciatura en } \\
\text { Ciencias Sociales con } \\
\text { mención en Desarrollo } \\
\text { Local. }\end{array}$ & $\begin{array}{l}\text { Facilitador/a. } \\
\text { Habilidades en el uso } \\
\text { de las tecnologías de la } \\
\text { información y de la comu- } \\
\text { nicación. } \\
\text { Desempeñarse en dife- } \\
\text { rentes campos. } \\
\text { Gerencia y Administración } \\
\text { de proyectos. } \\
\text { Investigación. } \\
\text { Enfoque social y de desa- } \\
\text { rrollo. }\end{array}$ & Estadística. \\
\hline
\end{tabular}




\section{LA EDUCACIÓN SUPERIOR EN LA REGIÓN AUTÓNOMA ATLÁNTICO NORTE}

\begin{tabular}{|c|c|c|}
\hline Carrera & $\begin{array}{c}\text { Fortalezas del perfil } \\
\text { profesional para } \\
\text { empleo }\end{array}$ & $\begin{array}{l}\text { Debilidades del perfil } \\
\text { profesional para empleo }\end{array}$ \\
\hline $\begin{array}{l}\text { Licenciatura en } \\
\text { Administración de } \\
\text { Empresas }\end{array}$ & $\begin{array}{l}\text { La mención en Banca y } \\
\text { Finanzas. } \\
\text { Manejo de Recursos } \\
\text { Humanos. } \\
\text { Gerencia. }\end{array}$ & $\begin{array}{l}\text { La mención en Recursos Naturales. } \\
\text { Falta de computación. } \\
\text { Falta de prácticas. } \\
\text { Falta de conocimientos de las len- } \\
\text { guas indígenas. } \\
\text { Falta de conocimientos de orga- } \\
\text { nización de compras, suministro } \\
\text { y manejo de bodega, relaciones } \\
\text { humanas, higiene y seguridad } \\
\text { ocupacional-empresarial, diseño } \\
\text { y elaboración de pequeños nego- } \\
\text { cios. } \\
\text { Liderazgo y control de los recursos } \\
\text { humanos. } \\
\text { Falta de conocimientos del Marco } \\
\text { Legal. } \\
\text { Mayores conocimientos en el área } \\
\text { contable ya que los conocimientos } \\
\text { son generales y no específicos. }\end{array}$ \\
\hline $\begin{array}{l}\text { 8. Licenciatura en } \\
\text { Educación Intercultural } \\
\text { Bilingüe }\end{array}$ & $\begin{array}{l}\text { Transformación curricular. } \\
\text { Competencias educativas. } \\
\text { Conocimientos de gramá- } \\
\text { tica del idioma mayangna. }\end{array}$ & $\begin{array}{l}\text { Más conocimiento del idioma es- } \\
\text { pañol. }\end{array}$ \\
\hline
\end{tabular}

Existen factores que limitan la inserción en el mundo laboral según el perfil de la carrera, entre ellos tenemos:

En las carreras de Ingeniería Agroforestal, Zootecnia y Administración son:

- Sexo.

- Político partidario.

- Experiencia profesional.

- Celos profesionales.

Coincidiendo con el Informe sobre la Educación Superior en América Latina y el Caribe 2000-2005, que la educación terciaria ofrece una garantía para quien apuesta 
a prolongar su formación académica y a través de ello acceder a empleos "calificados" y de "alta productividad". Sin embargo, en América Latina, los avances realizados no han sido suficientes para modificar profundamente la división sexual del trabajo en este terreno.

En Sociología y Desarrollo Local son:

- Político partidario.

- Pocas oportunidades de trabajo o campo laboral reducido.

- Edad.

- Experiencia profesional.

Las personas graduadas desean realizar estudios de postgrado con el objetivo de reforzar, actualizar sus conocimientos y especializarse, para esto le proponen a la universidad temas como:

- Desarrollo rural.

- Formulación, monitoreo y evaluación de proyectos.

- Metodología de la investigación.

- Pedagogía.

- Inglés.

- Administración de Recursos Humanos.

- Administración escolar.

- Ciencias Sociales.

- Antropología.

- Lingüística.

- Manejo de Recursos Naturales.

- Economía Ambiental.

- Manejo de ganado.

- Administración de negocios. 


\section{LA EDUCACIÓN SUPERIOR EN LA REGIÓN AUTÓNOMA ATLÁNTICO NORTE}

\section{Conclusiones}

- En URACCAN Las Minas el 57\% de las personas graduadas son del sexo femenino, aunque la distribución por género varía entre carreras; así, por ejemplo, en Ingeniería Agroforestal los hombres representan el 73.2\% de los titulados, mientras que en Sociología, Administración de Empresas y Ciencias de la Educación predominan las mujeres, con el $91.4 \%, 85.4 \%$ y $58.5 \%$ respectivamente.

- El $11 \%$ pertenece a los pueblos miskitus y mayangnas; los mestizos representan la mayoría con el $89 \%$, por lo que se infiere que en este recinto acceden y egresan menos indígenas y más mestizos.

- La edad promedio para el total de titulados es de 36.41 años, la edad más representativa es 30 años, la mínima 23 años y 62 años la máxima, esta última no representativa.

- Existe más mujeres jóvenes entre los 25 años. El rango de edad en los hombres es mayor y está representado por 30 años en adelante.

- La mayoría de personas graduadas de URACCAN Recinto Las Minas se pueden localizar en el municipio de Siuna, con un 56.3\%; en el municipio de Rosita con 28.5\%; en el municipio de Bonanza el $10.8 \%$ y en menor proporción os municipios de Mulukukú, Waslala y Nindiri (1.9\%, $1.3 \%$ y 0.6 respectivamente).

- Las carreras que más graduaciones tienen son Ingeniería Agroforestal, Licenciatura en Administración de Empresas y Licenciatura en Sociología.

- $\quad$ El 91\% de personas graduadas se encuentran empleadas.

- La mayor parte de personas graduadas de la URACCAN son asalariados y representan el $88.06 \%$, seguidos por quienes ocupan una posición de patrones o empleadores de su propio negocio con el 5.84\%.

- El 75\% de las graduaciones pertenecen a la generación 2001-2006 y se encuentran laborando en instituciones del sector estatal, el resto se ubica en organizaciones privadas y otros.

- La mayoría se encuentra desempeñando funciones docentes y administrativas.

- Las personas graduadas que son mejor remuneradas monetariamente son los de la carrera de Ingeniería Agroforestal y de la Licenciatura en Ciencias Sociales con mención en Desarrollo Local con salarios de $C \$ 7026.00$ y $C \$ 5459.00$ respectivamente). 
- Aquellas y aquellos estudiantes que cursaron las carreras de Ciencias de la Educación con mención en Historia e Ingeniería en Zootecnia, el 100\% están ocupados según el perfil de la carrera.

- El 90\% de las personas graduadas de esa generación se sienten satisfechas con la formación recibida.

\section{Lista de referencias}

ACESAR - Agencia Centroamericana de Acreditación de la Educación Superior en el Sector Agroalimentario y de Recursos Naturales - (2006). Guía de Evaluación con Fines de Acreditación de Programas Académicos en la Educación Superior para el Sector Agroalimentario y de Recursos Naturales. Universidad de San Carlos de Guatemala, Ciudad de Guatemala.

Fernández, N. (2005). Estudio La evaluación y la acreditación de la calidad de la educación superior en América Latina y el Caribe. Situación, tendencias y perspectivas.

Jaramillo, A; Ortiz, J; Zuluaga, E; Almonacid, P y Acebedo, S. (2002). Impacto social de los programas de pregrado. UNIVERSIDAD EAFIT. Obtenido el 21 de Diciembre del 2006 en www.eafit.edu.co/planeacion/sistemacalidad/procesoAcredita... sentirdelosEgresados.pdf.

López, H. (1996). La Educación Superior en Antioquia: Mercado educativo, mercado laboral e indicadores de reputación, selectividad/graduación y éxito laboral para los diversos programas. Medellín: CIDE, $154 \mathrm{p}$.

Red GRADUA2/ Asociación Columbus, (2006). Manual de instrumentos y recomendaciones sobre el seguimiento de egresados. Monterrey, México.

Sánchez, S. \& Mordt, M. (2005). Estudio de impacto de EARTH. Costa Rica, 45 p.

Suárez, G. (S/f.). Evaluación de impactos sociales en la SUM Aguada de pasajeros. Obtenido el 23 de Diciembre del 2006 en www.monografias.com.

Téllez, M. y González, H. (2004). Las políticas para la educación superior en Venezuela: un espacio de diálogo entre el Estado y las instituciones. En La Universidad se Reforma II. UCV; ORUS; UNESCO/IESALC; UPEL; MES. Caracas, pág. 155.

UNESCO (1998). Conferencia Mundial sobre Educación Superior. Informe Final, París. 